\title{
Time-dependent deformations of limestone powder type self-compacting concrete
}

\author{
G. Heirman ${ }^{\text {a,* }}$, L. Vandewalle ${ }^{\mathrm{a}}$, D. Van Gemert ${ }^{\mathrm{a}}$, V. Boel ${ }^{\mathrm{b}}$, K. Audenaert $^{\mathrm{c}}$, G. De Schutter ${ }^{\mathrm{c}}$, B. Desmet $^{\mathrm{d}}$, \\ J. Vantomme ${ }^{\mathrm{d}}$ \\ a Reyntjens Laboratory, Department of Civil Engineering, K.U. Leuven, Belgium \\ ${ }^{\mathrm{b}}$ Faculty of Applied Engineering Science, University College Ghent, Belgium \\ ${ }^{\mathrm{c}}$ Magnel Laboratory for Concrete Research, Department of Structural Engineering, Ghent University, Belgium \\ ${ }^{\mathrm{d}}$ Department of Civil and Materials Engineering, Royal Military Academy, Belgium
}

\section{A R T I C L E I N F O}

\section{Article history:}

Received 17 January 2008

Received in revised form

4 April 2008

Accepted 7 April 2008

Available online 19 May 2008

\section{Keywords:}

Time-dependent deformations

Shrinkage

Creep

Powder type self-compacting concrete

Limestone powder

\begin{abstract}
A B S T R A C T
Due to its different mix composition (e.g. use of superplasticizer, lower water/powder ratio (W/P) and higher paste volume) and its denser microstructure, different mechanisms and magnitudes concerning the time-dependent deformability, i.e. shrinkage and creep, hold for limestone powder type selfcompacting concrete (SCC). For this reason, experimental investigations concerning the shrinkage and creep behaviour of 7 limestone powder type SCC mixtures and 1 reference, traditionally vibrated, concrete mixture (TC1) are performed. The water/cement ratio $(\mathrm{W} / \mathrm{C})$, cement/powder ratio $(\mathrm{C} / \mathrm{P})$, aggregate type and cement type are studied.

The experimental data have been used to verify the accuracy of the CEB-FIP Model Code 1990 (MC-90) in terms of long-term deformations. Test results revealed generally higher shrinkage and creep deformations for the SCC mixtures compared with the TC1 mix. However, whereas the shrinkage deformations are underestimated by MC-90 the creep and overall behaviour of the limestone powder type SCC mixtures are rather well predicted by the same model. In order to properly predict the timedependent behaviour of limestone powder type SCC in cases of concrete structures (highly) sensitive to shrinkage and creep, a modification of the MC-90 in terms of the total shrinkage strain prediction is proposed by the authors. For creep, test results revealed that the MC-90 creep coefficient prediction could remain unmodified for limestone powder type SCC application.
\end{abstract}

(C) 2008 Elsevier Ltd. All rights reserved.

\section{Introduction}

Placement of traditionally vibrated concrete (TC) requires compaction by vibration. Durability problems related to bad compaction led to the introduction of self-compacting concrete (SCC) in Japan at the beginning of the 1980s [1]. SCC is able to flow and consolidate under its own weight, completely filling the formwork even in the presence of dense reinforcement, whilst maintaining homogeneity and without the need for any additional compaction effort. In order to comply with this definition, fresh SCC mixtures must possess following key properties:

(1) Filling ability: the ease of flow of fresh concrete when unconfined by formwork and/or reinforcement.

\footnotetext{
* Corresponding address: K.U. Leuven, Department of Civil Engineering, Reyntjens Laboratory, Kasteelpark Arenberg 40 bus 2448, 3001 Heverlee, Belgium. Tel.: +32163216 79; fax: +3216321976.

E-mail address: Gert.Heirman@bwk.kuleuven.be (G. Heirman).
}

(2) Passing ability: the ability of fresh concrete to flow through tight openings such as spaces between steel reinforcing bars without segregation or blocking.

(3) Resistance to segregation: the ability of concrete to remain homogeneous in composition in fresh state.

The first two properties are achieved by using a high-range water-reducing (HRWR) admixture, mostly based on (modified) polyacrylates (PA) or polycarboxylate ethers (PCE), also called a "3rd generation" superplasticizer. In order to achieve a sufficiently high resistance to segregation, the viscosity of the mixture must be increased compared to TC. This can be done in three ways, mostly depending on readily available materials: (a) using a higher powder content: "powder type" SCC, (b) using a viscosity modifying agent (VMA): "VMA type" SCC, or (c) using both a higher powder content and VMA: "Combination type" SCC.

Besides cement, the European powder type SCC (having a total powder content of about $550-650 \mathrm{~kg} / \mathrm{m}^{3}$ ) mostly uses mineral additions like limestone powder, quartzite powder, fly ash or silica fume in order to reduce heat generation during cement 
hydration. The VMA type SCC, mostly used in North America, makes use of a VMA, mostly based on polyethylene-glycol or biopolymers (like welan gum) and has a total powder content of about $350-450 \mathrm{~kg} / \mathrm{m}^{3}$. The combination type SCC uses both a VMA and a total powder content of about $450-550 \mathrm{~kg} / \mathrm{m}^{3}$.

The SCC mixtures used in this paper are all based on the powder type SCC philosophy, using readily available materials in Belgium. Ground limestone powder is used as mineral addition for all the SCC mixtures presented here. This type of mineral addition is mostly used in both precast and on site Belgian SCC production.

In this way, it is clear that concrete mixtures with a different paste volume and (pore) microstructure [2] are formed compared to TC. This means that the basic processes influencing the shrinkage and creep mechanisms (loss of moisture, carbonation and selfdesiccation in case of shrinkage, movement and rearrangement of absorbed water layers and loss of moisture in case of creep) are different, eventually resulting in a different time-dependent behaviour of SCC compared to TC.

A knowledge of the time-dependent deformability of hardened concrete is nevertheless necessary for a durable structural design practise, because it has a considerable influence on the performance of reinforced and prestressed concrete structures. Therefore, shrinkage and creep must be properly considered when dealing with safety and reliability in terms of limit-states approach, in particular when the structures that are examined result from a complex sequence of construction phases, loading and restraint deformation conditions [3].

To date, research about the performance of SCC structures, especially concerning the changes of long-term performance, is rather limited. Besides, literature data concerning the timedependent behaviour of SCC are often contradictory because of differences in formulations (both mix design philosophy and locally available materials), experimental procedures (e.g. age and rate of loading, specimen size, curing conditions) and material properties (e.g. moisture content, stress/strength ratio). Therefore, it is not surprising that the time-dependent deformability results reported in the literature [4-21] scatter over a wide range, going from lower, over equal, to higher time-dependent deformations for SCC compared to TC. In a RILEM state-of-the-art report on SCC [22], a similar statement is made: "Shrinkage and creep are as most concrete properties dependent on several parameters while the basis for comparisons is important for the conclusions drawn. ... The choice of constituent materials will, to a lesser or bigger extent, influence the properties".

Therefore, it is the authors' conviction that SCC cannot be treated as a group of materials with a comparable hardened state behaviour: although different SCC mixtures can show a comparable fresh state behaviour, they can show a very different hardened state behaviour (mechanical properties, durability, timedependent behaviour, ...) due to different strategies for mixture proportioning and different locally available materials.

In addition, existing prediction models in terms of long-term deformations such as CEB-FIP Model Code (MC-90) [23], model B3 [24], ACI-209 [25] and JSCE-2002 [26] do not consider the effect of the different mix composition of SCC (mineral additions, chemical admixtures, higher paste volumes, ...).

For those reasons, shrinkage and creep tests were performed in the framework of a Belgian research project concerning the "transport properties of potentially aggressive media in SCC and relation with durability" [27] in order to investigate the timedependent behaviour of limestone powder type SCC. As stated above, this type of SCC is most frequently used in Belgian SCC production.
Table 1

Particle density of materials $\left[\mathrm{g} / \mathrm{cm}^{3}\right]$

\begin{tabular}{ll}
\hline River sand 0/5 & 2.63 \\
River gravel 4/14 & 2.63 \\
Crushed limestone 4/14 & 2.69 \\
CEM I 42.5 R & 3.12 \\
CEM III/A 42.5 N LA & 2.97 \\
Limestone filler & 2.65 \\
Superplasticizer & 1.10 \\
\hline
\end{tabular}

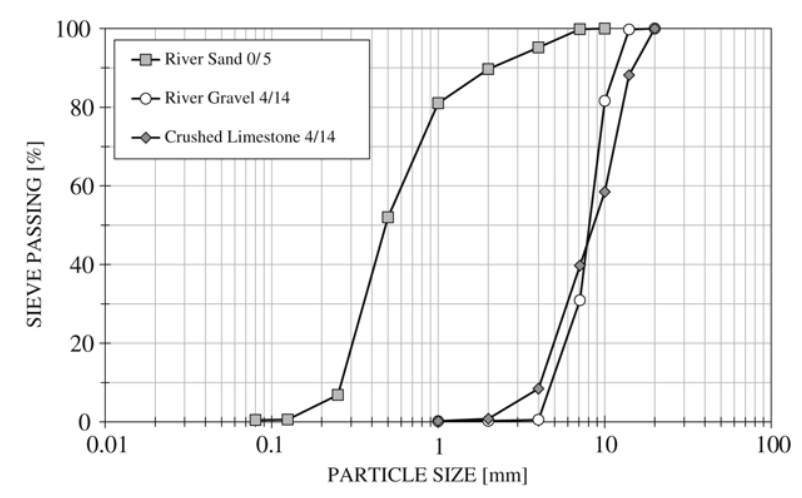

Fig. 1. Aggregate particle size distribution.

\section{Materials and experimental techniques}

\subsection{Characterisation of materials}

\subsubsection{Materials used}

Siliceous river sand $0 / 5$ is used as a fine aggregate. For the coarse aggregate either siliceous river gravel $4 / 14$ or crushed limestone $4 / 14$ is used. The crushed limestone $4 / 14$ has been composed of the fractions $2 / 7$ and $7 / 14$ in order to get an almost similar grading curve as for gravel 4/14. A HOLCIM portland cement CEM I $42.5 \mathrm{R}$ and blast furnace slag cement CEM III/A $42.5 \mathrm{~N}$ LA (both according to EN 197-1:2000) and an OMYA finely ground limestone addition (Betocarb P2 Mq) are used as "powder". A PCE superplasticizer, Glenium51 con.35\% from BASF was added in the SCC mixtures.

\subsubsection{Particle density}

In order to determine the paste volume, the particle densities of the aggregates and the powders are determined according to EN 1097-6:2000 and EN 1097-7:1999, respectively. The results are presented in Table 1 . The density of the superplasticizer is taken from its technical data sheet.

\subsubsection{Grading curves}

The grading curves of the aggregates (Fig. 1) are determined according to EN 933-1:1997 and EN 12620:2002. The grading curves of the powders (Fig. 2) are determined by means of laser diffraction, using the Malvern MASTERSIZER S apparatus (measuring range $0.05 \ldots 900 \mu \mathrm{m}$ ). The Blaine fineness of both cement types is determined according to EN 196-6:1991. The results are corrected to $20^{\circ} \mathrm{C}$ and are $3510 \mathrm{~cm}^{2} / \mathrm{g}$ and $4320 \mathrm{~cm}^{2} / \mathrm{g}$ for CEM I 42.5 R and CEM III/A 42.5 N LA, respectively.

\subsection{Mixture proportions}

In the experimental part of the research project, 8 different mix compositions are tested with regard to shrinkage and creep. They consist of 1 traditionally vibrated concrete mixture (TC1) and 7 limestone powder type SCC mixtures, where SCC1 is the reference SCC-mixture. For the SCC mixtures, the total amount of powder (i.e. cement + limestone powder) was fixed at $600 \mathrm{~kg} / \mathrm{m}^{3}$ and the 


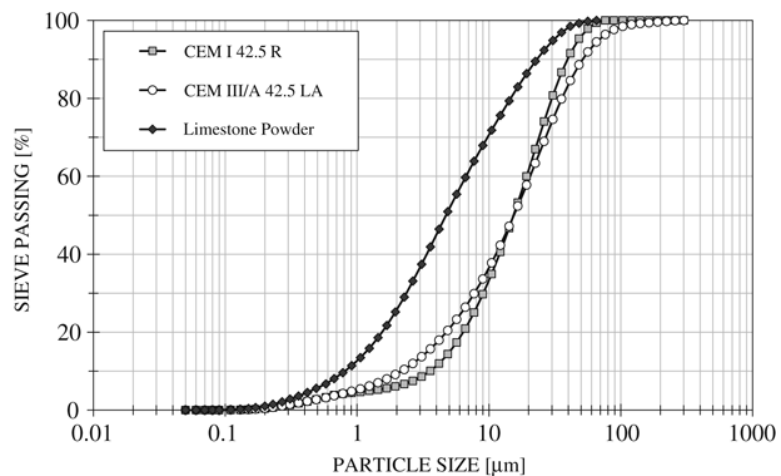

Fig. 2. Powder particle size distribution.

Table 2

Mix composition of TC1

\begin{tabular}{lll}
\hline Mixture & & TC1 \\
\hline River gravel $4 / 14$ & {$\left[\mathrm{~kg} / \mathrm{m}^{3}\right]$} & 1225 \\
River sand 0/5 & {$\left[\mathrm{kg} / \mathrm{m}^{3}\right]$} & 640 \\
CEM I 42.5 R & {$\left[\mathrm{kg} / \mathrm{m}^{3}\right]$} & 360 \\
Water & {$\left[1 / \mathrm{m}^{3}\right]$} & 165 \\
W/C & {$[-]$} & 0.46 \\
C/P & {$[-]$} & 1.00 \\
W/P & {$[-]$} & 0.46 \\
Slump & {$[\mathrm{mm}]$} & 14 \\
Flow & {$[-]$} & 1.89 \\
Air content & {$[\%]$} & 1.1 \\
$f_{c, \text { cub150,28d }}$ & $\left.4 \mathrm{~N} / \mathrm{mm}^{2}\right]$ & 47.6 \\
Total volume & {$\left[1 / \mathrm{m}^{3}\right]$} & 991 \\
Paste volume & {$\left[1 / \mathrm{m}^{3}\right]$} & 281 \\
Paste volume & {$[\%]$} & 28.3
\end{tabular}

amount of PCE superplasticizer was determined in order to obtain a suitable flowability without segregation. All SCC mixtures showed a self-levelling behaviour in the U-box test. Besides comparing TC to SCC, the influence of the following parameters is studied: type of cement (CEM I 42.5 R versus CEM III/A 42.5 N LA,), cement/powder and water/cement ratio and type of aggregate (river gravel versus crushed limestone).

An overview of the different mixture compositions is given in Tables 2 and 3. Furthermore, the fresh state properties, the
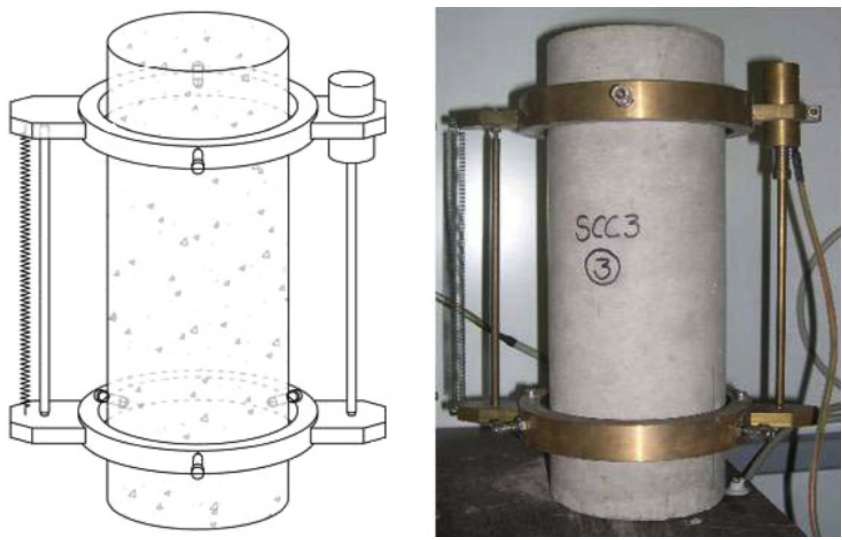

Fig. 3. Overview of the measuring device (left: schematic, right: real setup).

$28 \mathrm{~d}$ compressive strength on $150 \mathrm{~mm}$ cubes and the paste volume are also represented. Note that $\mathrm{W} / \mathrm{C}, \mathrm{C} / \mathrm{P}, \mathrm{W} / \mathrm{P}$ are the water/cement, thecement/powder and the water/powder ratio by mass, respectively.

\subsection{Test specimens and test setup}

For each concrete mixture, 8 cylindrical test specimens $(\phi=$ $120 \mathrm{~mm}, h=300 \mathrm{~mm}$ ) were manufactured and kept at $20 \pm 2{ }^{\circ} \mathrm{C}$ and $>90 \%$ R.H. for one day. Afterwards, the test specimens were demoulded, equipped with their measuring devices and cured immediately under constant $\left(20 \pm 2{ }^{\circ} \mathrm{C}\right.$ and $60 \pm 5 \%$ R.H. $)$ climatic test conditions.

Overviews of the measuring device and some of the shrinkage specimens are given in Fig. 3 and Fig. 4(left). The bottom ring is immovably fixed on the concrete cylinder by 3 points while the upper ring is fixed in 2 opposite points, so it can rotate around the axis formed by the 2 fixation points. At one side of the frame, a small bar (and a spring to keep the bar under pressure) provides a fixed distance between the 2 rings at this side. At the other side, a second small bar holds the core of the Linear Variable Differential Transducer (LVDT) in order to measure the deformations. A more detailed description of the measuring device is described in $[28,29]$. Due to the lever effect of the upper ring, the mean cylindrical concrete deformation is half the deformation measured by the

Table 3

Mix compositions of the SCC mixtures

\begin{tabular}{|c|c|c|c|c|c|c|c|c|}
\hline Mixture & & SCC1 & $\mathrm{SCC} 3$ & SCC5 & SCC14 & SCC15 & SCC16 & SCC17 \\
\hline River gravel 4/14 & {$\left[\mathrm{kg} / \mathrm{m}^{3}\right]$} & 698 & 698 & 698 & 707 & 683 & - & 675 \\
\hline Cr. Limestone 4/14 & {$\left[\mathrm{kg} / \mathrm{m}^{3}\right]$} & - & - & - & - & - & 698 & - \\
\hline River sand 0/5 & {$\left[\mathrm{kg} / \mathrm{m}^{3}\right]$} & 853 & 853 & 853 & 865 & 835 & 853 & 825 \\
\hline CEM I 42.5 R & {$\left[\mathrm{kg} / \mathrm{m}^{3}\right]$} & 360 & - & 300 & 360 & 360 & 360 & 360 \\
\hline CEM III/A 42.5 LA & {$\left[\mathrm{kg} / \mathrm{m}^{3}\right]$} & - & 360 & - & - & - & - & - \\
\hline Limestone powder & {$\left[\mathrm{kg} / \mathrm{m}^{3}\right]$} & 240 & 240 & 300 & 240 & 240 & 240 & 240 \\
\hline Water & {$\left[1 / \mathrm{m}^{3}\right]$} & 165 & 165 & 165 & 144 & 198 & 165 & 216 \\
\hline Superplasticizer & {$\left[1 / \mathrm{m}^{3}\right]$} & 2.75 & 2.5 & 2.4 & 4.0 & 2.0 & 3.6 & 2.0 \\
\hline $\mathrm{W} / \mathrm{C}$ & {$[-]$} & 0.46 & 0.46 & 0.55 & 0.40 & 0.55 & 0.46 & 0.60 \\
\hline $\mathrm{C} / \mathrm{P}$ & {$[-]$} & 0.60 & 0.60 & 0.50 & 0.60 & 0.60 & 0.60 & 0.60 \\
\hline $\mathrm{W} / \mathrm{P}$ & {$[-]$} & 0.28 & 0.28 & 0.28 & 0.24 & 0.33 & 0.28 & 0.36 \\
\hline Slump-flow & {$[\mathrm{mm}]$} & 875 & 905 & 785 & 775 & 920 & 875 & 805 \\
\hline V-funnel flow time & {$[s]$} & 7.9 & 7.0 & 8.1 & 20.0 & 3.5 & 8.0 & 2.8 \\
\hline Air content & [\%] & 1.7 & 0.7 & 2.3 & 2.5 & 1.1 & 1.1 & 0.4 \\
\hline$f_{c, c u b 150,28 d}$ & {$\left[\mathrm{~N} / \mathrm{mm}^{2}\right]$} & 57.1 & 69.2 & 49.0 & 68.4 & 46.7 & 73.3 & 39.9 \\
\hline Total volume & {$\left[1 / \mathrm{m}^{3}\right]$} & 964 & 970 & 968 & 953 & 984 & 959 & 996 \\
\hline Paste volume & {$\left[1 / \mathrm{m}^{3}\right]$} & 374 & 379 & 377 & 354 & 406 & 374 & 424 \\
\hline Paste volume & [\%] & 38.7 & 39.1 & 38.9 & 37.1 & 41.2 & 39.0 & 42.6 \\
\hline
\end{tabular}

Note: SCC mixtures are numbered according to laboratory sequence. 

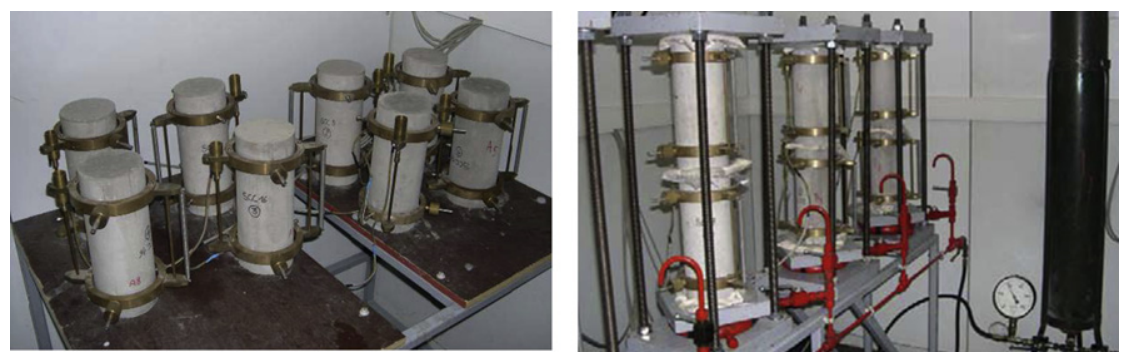

Fig. 4. Shrinkage (left) and creep (right) test setup.

LVDT. In this way, the concrete strains [\%o or $\mathrm{mm} / \mathrm{m}$ ] are calculated as:

$\varepsilon_{c}(t)=\frac{1}{2} \frac{\delta_{t}-\delta_{0}}{L_{b}} \frac{10^{3}}{C}$

with $\varepsilon_{c}(t)$ the concrete strain at time $t[\mathrm{~mm} / \mathrm{m}] ; L_{b}$ the LVDT measuring base $(=200 \mathrm{~mm}) ; \delta_{0}$ and $\delta_{t}$ the LVDT-reading at time $t_{0}(=1 d)$ and $t$ respectively [V] and $C$ the calibration constant of the LVDT $[\mathrm{V} / \mathrm{mm}]$.

After 28 days, 4 specimens of each concrete mixture were subjected to a uniaxial loading of $\pm 1 / 3$ of their compressive strength at 28 days (stored by $20 \pm 2{ }^{\circ} \mathrm{C}$ and $>90 \%$ R.H.). An overview of some creep specimens is given in Fig. 4(right). The creep load is transmitted to 2 superposed test specimens by means of a flat hydraulic jack. To keep the load constant during the test period, the jacks were connected with a pressure vessel, filled with nitrogen (90\%) and oil (10\%), in order to intercept the small volume changes due to the increasing creep deformations. Between the 2 test specimens and between the test specimens and the supporting frame, small bags with plaster are provided in order to eliminate the effect of the test specimens' surface roughness on the uniaxiality as much as possible.

\section{Shrinkage: Experimental results and discussion}

Several factors affect the shrinkage of concrete, including paste and aggregate volume, modulus of elasticity, aggregate type and size, (pore) microstructure and water content. A detailed discussion on all those factors is beyond the scope of this paper. Nonetheless, it is well accepted that aggregate volume has probably the greatest impact on restraining the shrinkage. As a result of the higher paste volume of powder type SCC compared to TC (about 40\% more for the SCC mixtures presented here, see Tables 2 and 3), higher shrinkage deformations of powder type SCC compared to TC are to be expected [30,31].

As mentioned above, shrinkage measurements started immediately after the equipment of the test specimens with their measuring devices (i.e. $\pm 24 \mathrm{~h}$ after casting). The results of the shrinkage measurements are represented in Fig. 5 (shrinkage measurements for each mixture: 4 specimen deformation curves and 1 mean deformation curve) and Fig. 6 (overview of mean shrinkage deformations for all mixtures). Fig. 5 gives information about the scatter of the measurements: mixtures TC1, SCC 1 and SCC16 show a very small scatter, while the other mixtures show a moderate, but still acceptable, scatter.

The following conclusions are drawn, based on Fig. 6 (SCC1 is used as reference mix):

- When comparing the different SCC mixtures with the traditionally vibrated mix TC1, higher shrinkage deformations are observed, due to the higher paste volume of the SCC mixtures. $[30,31]$ Remarkable is the substantially steeper rise of the deformations, particularly for young concrete aged up to 14 days, which decreases again with increasing age. This steeper rise can be related to the increased "flour grain portion", as stated in [32], resulting in a denser microstructure with smaller pores [33] and thus in higher (autogenous) shrinkage deformations compared to TC1.

- When replacing portland cement CEM I $42.5 \mathrm{R}$ by blast furnace slag cement CEM III/A 42.5 N LA (SCC3), a somewhat more flowable SCC mixture was obtained. The air content was more than halved (from 1.7 to $0.7 \%$ ) and a considerable increase in compressive strength (from 57.1 to $69.2 \mathrm{MPa}$ ) was observed. The combined effect of the higher compressive strength and the same amount of cement and water, explain the significant lower shrinkage deformations, compared with SCC1 and TC1.

- If the cement/powder ratio is decreased from 0.60 to 0.50 (SCC5), no significant difference in shrinkage behaviour is observed compared to SCC1. The reason for this observation can be explained by the occurrence of two counteracting phenomena: on the one hand, the decrease of cement content will also decrease the amount of CSH-gel formed and thus decrease the shrinkage deformations while, on the other hand, the higher air content $(2.3 \%)$ and lower compressive strength (49.0 MPa) will increase the shrinkage deformations. Both effects seem to compensate each other, resulting in a comparable shrinkage behaviour as for SCC1.

- The influence of the $\mathrm{W} / \mathrm{C}$ ratio is less clear than observed in other durability aspects [34]: SCC15 (W/C $=0.55$ ) shows comparable (keeping the early mentioned scatter in mind) shrinkage deformations compared with SCC1 $(\mathrm{W} / \mathrm{C}=0.46)$, while the observations concerning SCC14 (W/C $=0.40)$ and SCC17 $(\mathrm{W} / \mathrm{C}=0.60)$ correspond better to the expected shrinkage behaviour. Besides, it is remarkable that SCC15 is doing so well concerning its shrinkage behaviour. Its mix design (less aggregates and higher paste volume, slump-flow of 920 $\mathrm{mm}, \mathrm{V}$-funnel flow time of $3.5 \mathrm{~s}$ ) leads one to expect higher shrinkage deformations than those of SCC1. A firm explanation for this observation has not yet been found.

- If crushed limestone (SCC16) instead of river gravel is used as coarse aggregate, somewhat lower shrinkage deformations are observed, due to an increased compressive strength (73.3 $\mathrm{MPa}$ ) and the aggregate type (e.g. more irregular shape and rougher surface). It should be noted, however, that the difference is small: the negative effect of the higher paste volume seems to dominate the positive effect of the aggregate type on restraining shrinkage.

\section{Creep: Experimental results and discussion}

Given that SCC contains less aggregates (with negligible creep compared to that of the paste), i.e. $675-707 \mathrm{~kg} / \mathrm{m}^{3}$ for the SCC mixtures versus $1225 \mathrm{~kg} / \mathrm{m}^{3}$ for TC1, the creep deformations of powder type SCC are expected to be higher than for TC. On the other hand, higher strength and lower internal porosity (associated with both a lower water/powder ratio, i.e. $\mathrm{W} / \mathrm{P}=0.28$ for the 
SHRINKAGE DEFORMATIONS TC1

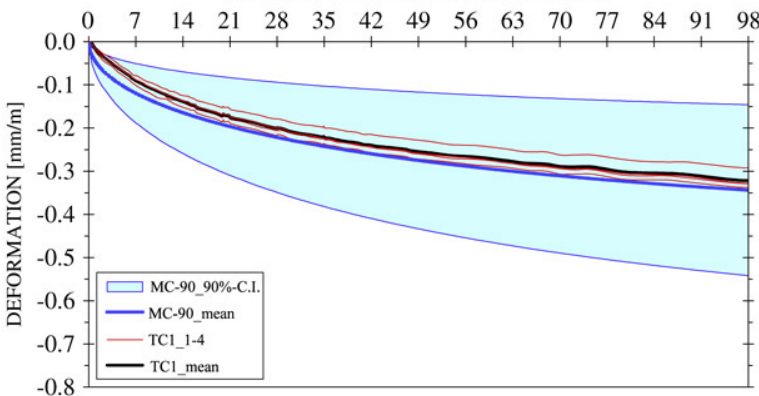

AGE AFTER DEMOULDING [days]

SHRINKAGE DEFORMATIONS SCC 3

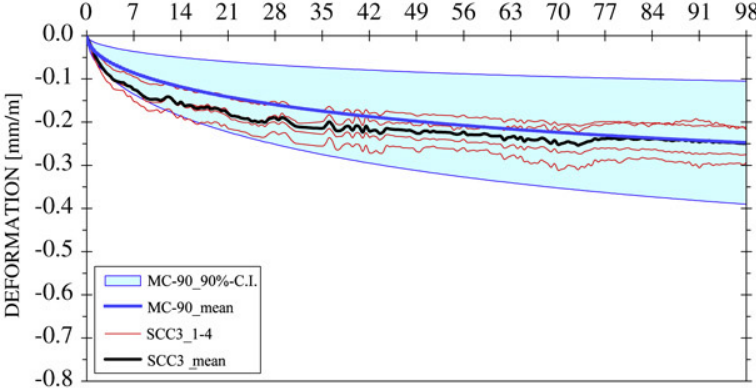

AGE AFTER DEMOULDING [days]

SHRINKAGE DEFORMATIONS SCC14

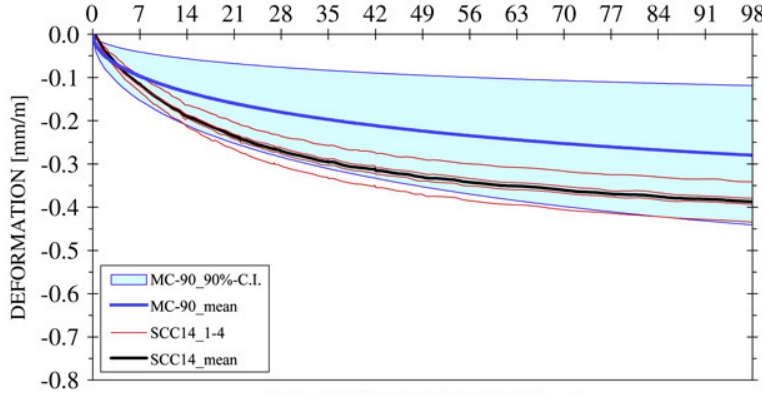

AGE AFTER DEMOULDING [days]

SHRINKAGE DEFORMATIONS SCC16

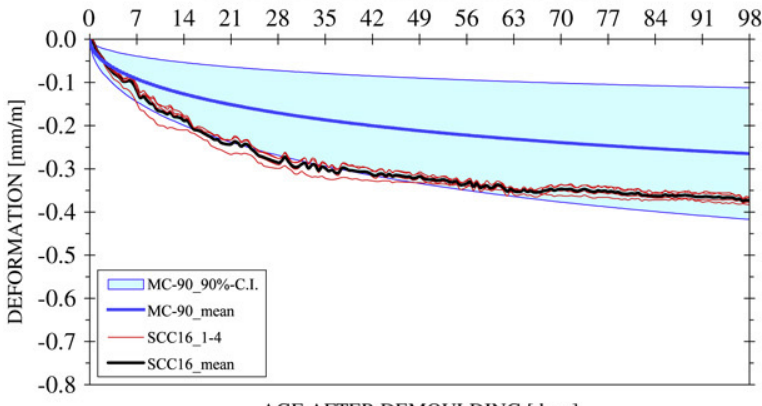

SHRINKAGE DEFORMATIONS SCC1

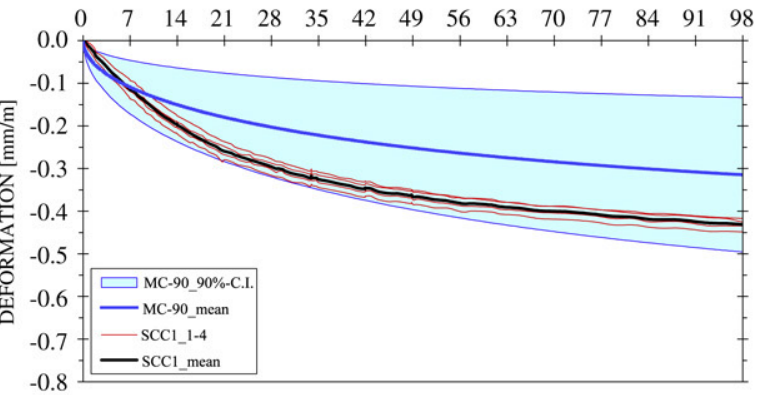

AGE AFTER DEMOULDING [days]

SHRINKAGE DEFORMATIONS SCC5

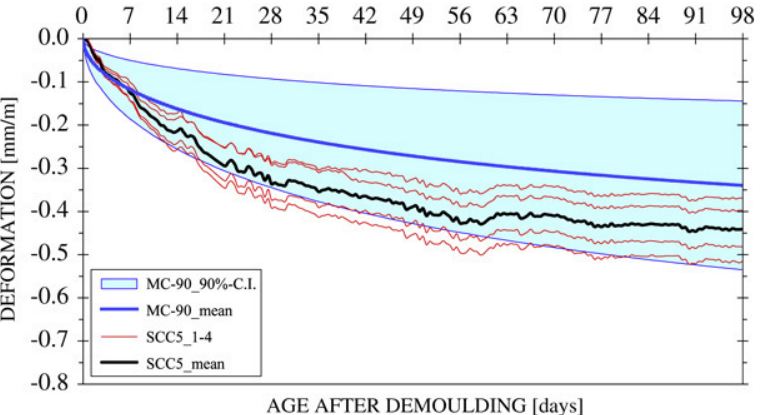

SHRINKAGE DEFORMATIONS SCC15

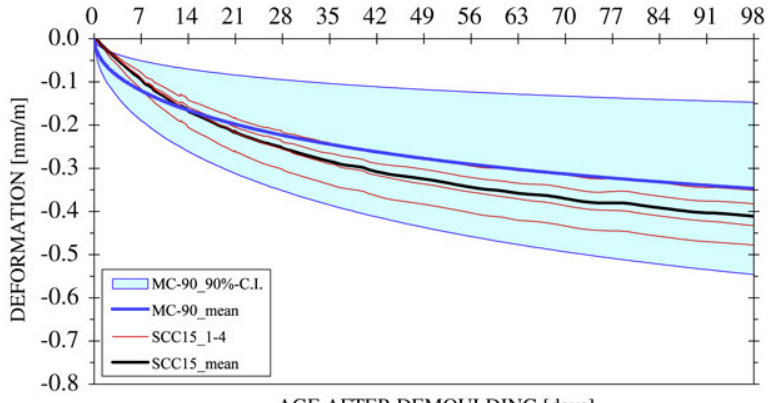

AGE AFTER DEMOULDING [days]

SHRINKAGE DEFORMATIONS SCC17

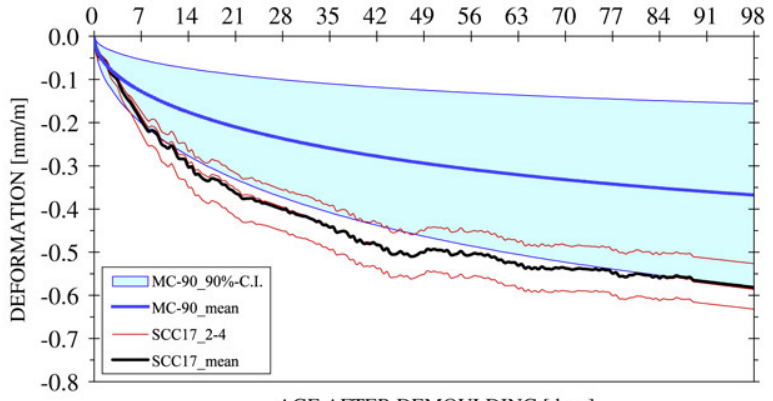

AGE AFTER DEMOULDING [days]

Fig. 5. Shrinkage measurements for each mixture, including MC-90 model $90 \%$ confidence interval.

SCC mixtures versus $\mathrm{W} / \mathrm{P}=0.46$ for TC1, and an equal water content of the powder type SCC mixtures compared to TC) may counteract the previous effect. These counteracting phenomena can also explain the occurrence of contradictory results reported in literature (besides to differences in formulations, experimental procedures and material properties, see above).

As stated above, the age of loading was set at 28 days for all creep measurements. The exact stress/strength ratio can be found in Table 4. The results of the total deformation measurements for each mixture are represented in Fig. 7 (4 specimen deformation curves and 1 mean deformation curve), also providing information about the scatter of the time-dependent measurements: mixtures
TC1, SCC1 and SCC14 show a very small scatter, while the other mixtures show a moderate, but still acceptable, scatter.

Contrary to the mean shrinkage deformations, it makes no sense to take all mean creep deformations together in one graph, since every mixture is loaded by a different creep load (Table 4). Instead, the creep coefficient $\phi\left(t, t^{\prime}\right)$ can be used to mutually compare the different mixtures, due to the linear relationship between the creep strain and the creep load, which is known to exist up to a given level of stress (up to about $50 \%$ and $65 \%$, respectively, for medium and high strength concrete). The creep coefficient $\phi\left(t, t^{\prime}\right)$ is defined as the ratio of the creep strain, $\varepsilon_{c c}\left(t, t^{\prime}\right)$, at time $t$ to the instantaneous elastic strain in a specimen subjected to a constant stress, $\varepsilon_{c i}\left(t^{\prime}\right)$, 
Table 4

Measured ( $\mathrm{m}$ ) and calculated $(\mathrm{c})$ instantaneous elastic strains $\varepsilon_{c i}\left(t^{\prime}\right)$

\begin{tabular}{|c|c|c|c|c|c|c|c|c|c|}
\hline Mixture & & TC1 & SCC1 & SCC3 & SCC5 & SCC14 & SCC15 & SCC16 & SCC17 \\
\hline$f_{c m}$ & {$\left[\mathrm{~N} / \mathrm{mm}^{2}\right]$} & 36.4 & 43.7 & 53.0 & 37.5 & 52.4 & 35.8 & 56.1 & 30.5 \\
\hline$\sigma_{C}\left(t^{\prime}\right)$ & {$\left[\mathrm{N} / \mathrm{mm}^{2}\right]$} & 10.1 & 14.1 & 20.6 & 11.3 & 16.4 & 10.1 & 20.6 & 11.3 \\
\hline SS ratio & {$[-]$} & 0.28 & 0.32 & 0.39 & 0.30 & 0.31 & 0.28 & 0.37 & 0.37 \\
\hline$E_{c i}$ & {$\left[\mathrm{~N} / \mathrm{mm}^{2}\right]$} & 33085 & 35154 & 37480 & 33406 & 37335 & 32875 & 38206 & 31195 \\
\hline $\begin{array}{l}\varepsilon_{c i, m}\left(t^{\prime}\right) \\
\varepsilon_{c i, c}\left(t^{\prime}\right)\end{array}$ & $\begin{array}{l}{[\mathrm{mm} / \mathrm{m}]} \\
{[\mathrm{mm} / \mathrm{m}]}\end{array}$ & $\begin{array}{l}-0.29 \\
-0.31\end{array}$ & $\begin{array}{l}-0.40 \\
-0.40\end{array}$ & $\begin{array}{l}-0.55 \\
-0.55\end{array}$ & $\begin{array}{l}-0.35 \\
-0.34\end{array}$ & $\begin{array}{l}-0.41 \\
-0.44\end{array}$ & $\begin{array}{l}-0.27 \\
-0.31\end{array}$ & $\begin{array}{l}-0.52 \\
-0.54\end{array}$ & $\begin{array}{l}-0.44 \\
-0.36\end{array}$ \\
\hline
\end{tabular}

$f_{c m}=$ mean $28 \mathrm{~d}$ compressive strength of the cylindrical test specimens; $t^{\prime}=$ age of loading; $\sigma_{c}\left(t^{\prime}\right)=$ creep load; SS ratio $=$ stress $/$ strength ratio $=\sigma_{c}\left(t^{\prime}\right) / f_{c m}$.

MEAN SHRINKAGE DEFORMATIONS - OVERVIEW

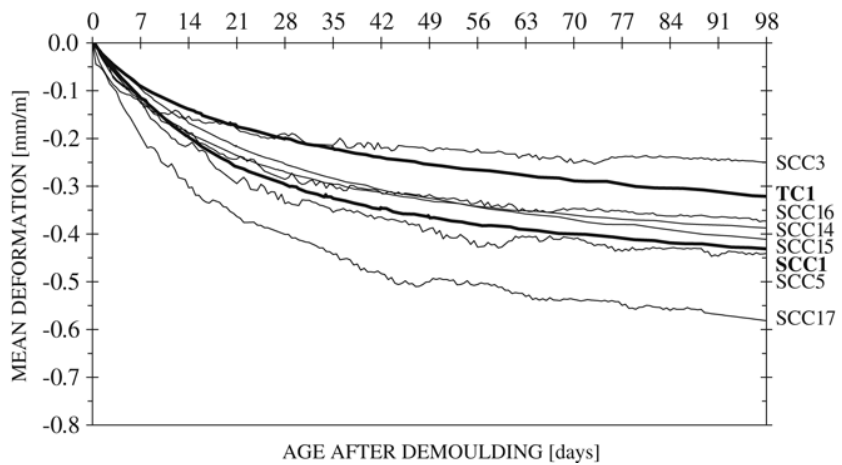

Fig. 6. Shrinkage measurements, overview of mean shrinkage deformations.

as expressed in the following equation:

$\phi\left(t, t^{\prime}\right)=\frac{\varepsilon_{c c}\left(t, t^{\prime}\right)}{\varepsilon_{c i}\left(t^{\prime}\right)} \equiv \frac{\varepsilon_{c t}\left(t, t^{\prime}\right)-\varepsilon_{c s}(t)}{\varepsilon_{c i}\left(t^{\prime}\right)}-1$

with $t^{\prime}$ the creep loading age $(=28 \mathrm{~d})$ and $\varepsilon_{c t}\left(t, t^{\prime}\right)$ and $\varepsilon_{c s}(t)$ the total and shrinkage strain at time $t$, respectively $[\mathrm{mm} / \mathrm{m}]$.

The instantaneous elastic strain can be measured $\left(\varepsilon_{c i, m}\left(t^{\prime}\right)\right)$ as the difference in strain immediately before and after applying the creep load. In this way, the obtained result is very depending on the exact time between applying the creep load and the next LVDTreading. To exclude this parameter, the instantaneous elastic strain can also be calculated $\left(\varepsilon_{c i, c}\left(t^{\prime}\right)\right)$ from the following equation:

$\varepsilon_{c i, c}\left(t^{\prime}\right)=\frac{\sigma_{c i}\left(t^{\prime}\right)}{E_{c i}}=\frac{\sigma_{c i}\left(t^{\prime}\right)}{21500 \cdot \sqrt[3]{f_{c m} / 10}}$

with $\sigma_{c}\left(t^{\prime}\right)$ the creep load $\left[\mathrm{N} / \mathrm{mm}^{2}\right], E_{c i}$ the $28 \mathrm{~d}$ tangent modulus of elasticity (according to [23]) and $f_{c m}$ the mean $28 \mathrm{~d}$ compressive strength of the cylindrical test specimens $\left[\mathrm{N} / \mathrm{mm}^{2}\right]$. The results are represented in Table 4.

The results of the creep coefficients are represented in Fig. 8 (creep coefficients for each mixture: 4 specimen deformation curves and 1 mean deformation curve) and Fig. 9 (overview of mean creep coefficients for all mixtures). The creep coefficient in function of time of each mixture is determined according to Eq. (2), using the mean shrinkage deformation (see Fig. 5) and the calculated instantaneous elastic strain (according to Eq. (3)) of the mixture concerned. In this way, Fig. 8 can be used to evaluate the isolated effect of the creep load on the scatter of the creep measurements: the traditionally vibrated mixture TC1 shows a very small scatter, while the self-compacting mixtures show a higher, moderate, scatter.

The following conclusions are drawn, based on Fig. 9 (SCC1 is used as reference mix):

- The SCC mixtures show higher creep deformations compared to TC1, due to the higher paste volume of the SCC mixtures. Similar to the shrinkage deformation behaviour, here a steeper rise of the creep coefficients is also observed for young loaded concrete, compared to TC1. Also here, the steeper rise of the creep coefficient can be related to the increased "flour grain portion" resulting in a denser microstructure with smaller pores [33] characterised by higher short-term creep deformations. It may be attributed to a change of the hygral equilibrium in the gas filled space which generates strain stresses and, eventually, microcracking, resulting in the shortterm component of creep [35,36].

- If portland cement CEM I $42.5 \mathrm{R}$ is replaced by blast furnace slag cement CEM III/A 42.5 N LA (SCC3), a similar behaviour compared to the shrinkage deformations can be noticed: lower creep coefficients are found compared with SCC1 and TC1. At first sight, this result is not consistent with known literature data concerning the use of ground blast furnace slag as cement replacement, where more creep is observed with increasing slag contents [37]. Besides, it is generally agreed that more rapid-hardening cements tend to creep least, due to the increased concrete matrix stiffness, making it more resistant to creep. However, in this particular case, a higher modulus of elasticity was found for SCC3 (due to higher strength and lower internal porosity for same amount of cement and water used, see Tables 2-4), compared to SCC1 and TC1, resulting in lower creep coefficients.

- If the cement/powder ratio is decreased from 0.60 to 0.50 (SCC5), a similar behaviour compared to the shrinkage deformations can be noticed: comparable creep coefficients are observed in comparison with SCC1. Also here, the counteracting phenomena of (a) an decreased CSH-gel content and (b) a higher air content and lower compressive strength compensate each other in terms of the resulting creep behaviour.

- The influence of the $\mathrm{W} / \mathrm{C}$ ratio is, in regard to the shrinkage deformations, more clear: SCC17 $(\mathrm{W} / \mathrm{C}=0.60)$ shows higher creep coefficients compared to SCC15 (W/C = 0.55), which, on his turn, shows higher creep coefficients compared to SCC1 $(\mathrm{W} / \mathrm{C}=0.46)$. The difference in $\mathrm{W} / \mathrm{C}$ ratio between SCC1 and SCC14 $(\mathrm{W} / \mathrm{C}=0.40)$ seems to be too small to influence the creep coefficient.

- If crushed limestone (SCC16) instead of river gravel is used as coarse aggregate, comparable creep coefficients are observed in comparison with SCC1. Also here, the negative effect of the higher paste volume dominates the positive effect of the aggregate type on creep resistance (as observed for the shrinkage deformations).

\section{Prediction of time-dependent deformations}

\subsection{Comparison of predicted and experimental time-dependent deformations}

From the existing time-dependent deformation prediction models mentioned above (CEB-FIP Model Code 1990 (MC-90) [23], model B3 [24], ACI-209 [25] and JSCE-2002 [26]), only the results for the MC-90 models are presented here, due to the geographical 
TOTAL DEFORMATIONS TC1
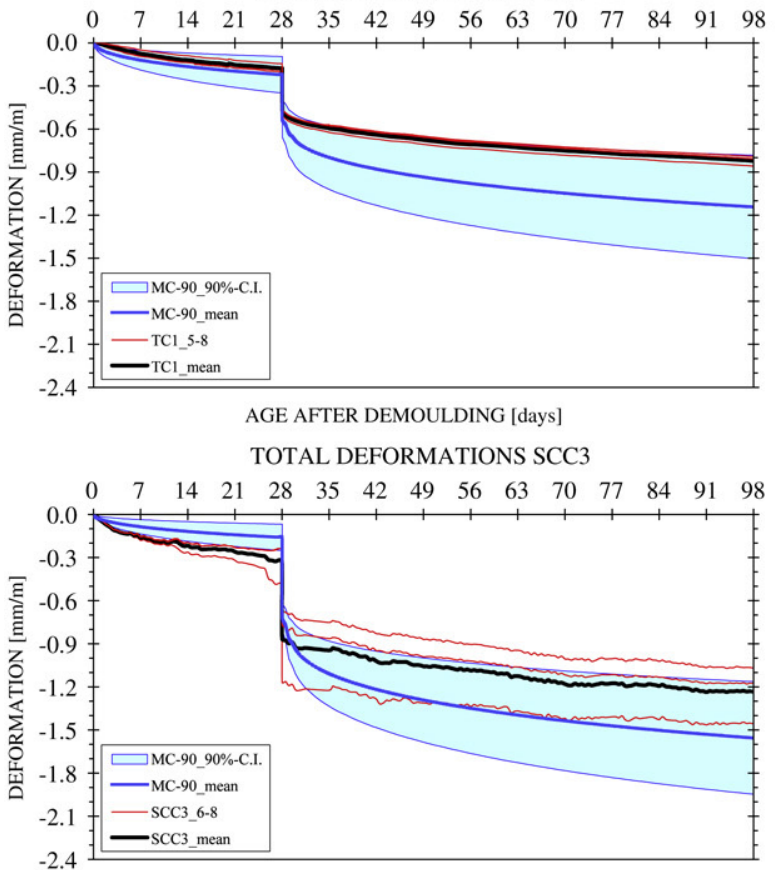

AGE AFTER DEMOULDING [days]

TOTAL DEFORMATIONS SCC14

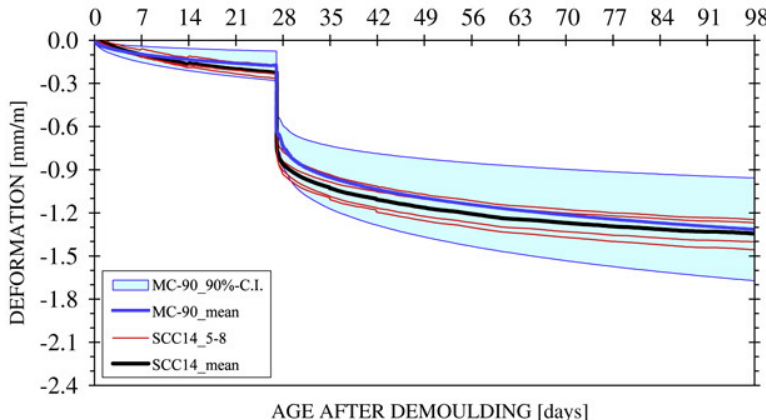

AGE AFTER DEMOULDING [days]

TOTAL DEFORMATIONS SCC16

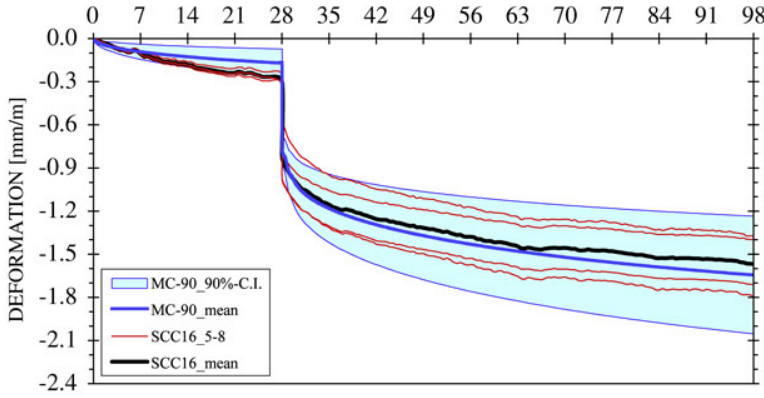

AGE AFTER DEMOULDING [days]
TOTAL DEFORMATIONS SCC1
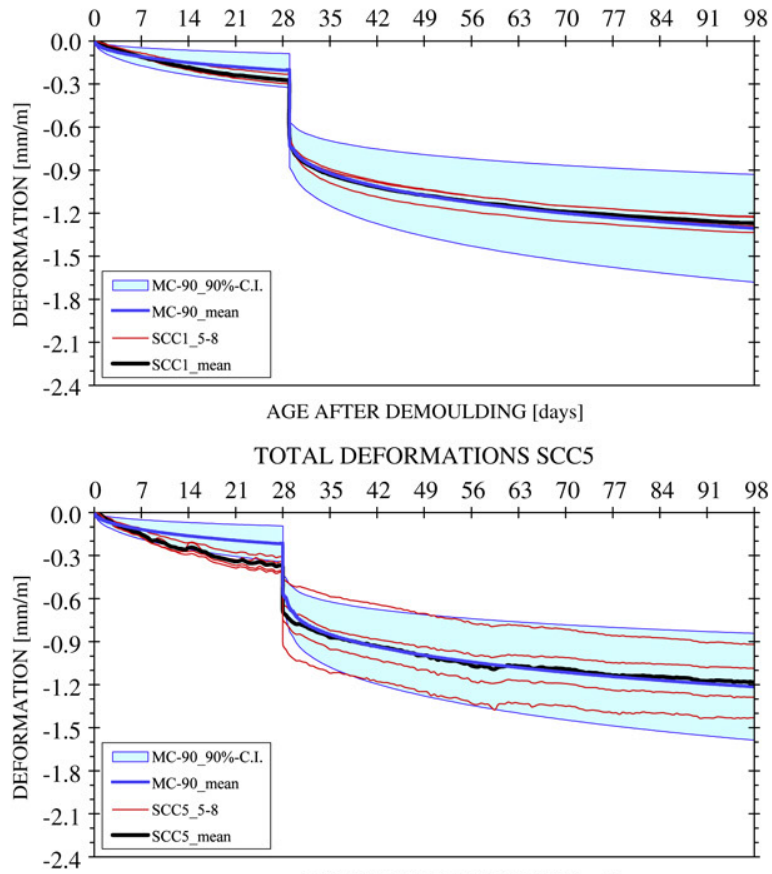

AGE AFTER DEMOULDING [days]

TOTAL DEFORMATIONS SCC15

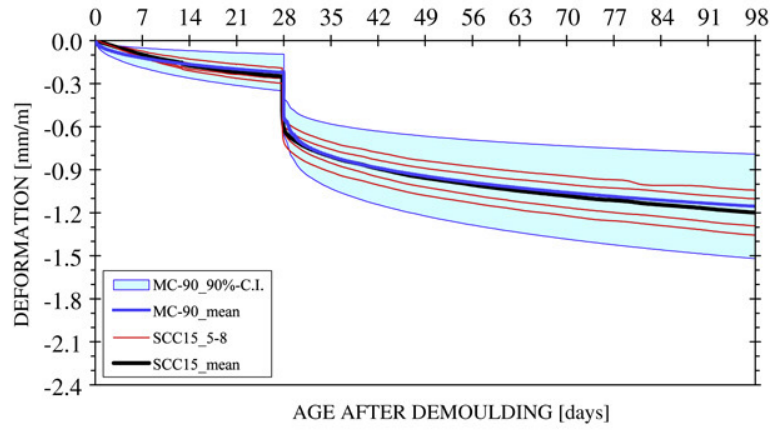

TOTAL DEFORMATIONS SCC17

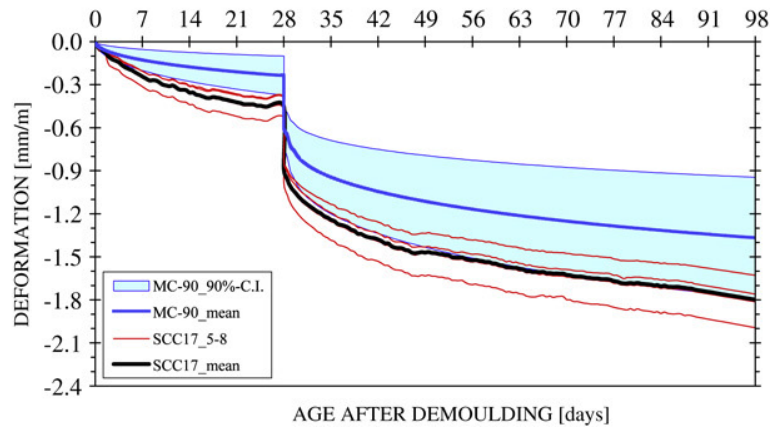

Fig. 7. Total deformation measurements for each mixture, including MC-90 model 90\% confidence interval.

analogy between MC- $90^{1}$ and the application of the "limestone powder type" mix design philosophy for SCC production (because of readily available materials). Besides, it was found that the other models do not necessary result in a better prediction of the long-term deformations, as illustrated in Fig. 10 for the different prediction models mentioned above in terms of the total shrinkage deformations of SCC1.

\footnotetext{
${ }^{1}$ MC-90 is used as reference document for the drawing up of the European standard EN 1992-1-1(:2005) - "Eurocode 2: Design of concrete structures - Part $1-1$ : General rules and rules for buildings".
}

In the MC-90 time-dependent deformation models, only parameters "normally known to the designer, i.e. characteristic compressive strength, member dimensions, mean relative humidity to which the member is exposed, age at loading, duration of loading and cement type" [23] are taken into account. For that reason, in combination with the totally different mix design philosophy of limestone powder type SCC compared to TC and thus different mix composition (e.g. use of mineral additions and chemical admixtures, higher paste volumes, ...), the experimentally obtained data were compared with the MC-90 prediction models in order to verify their accuracy in terms of 

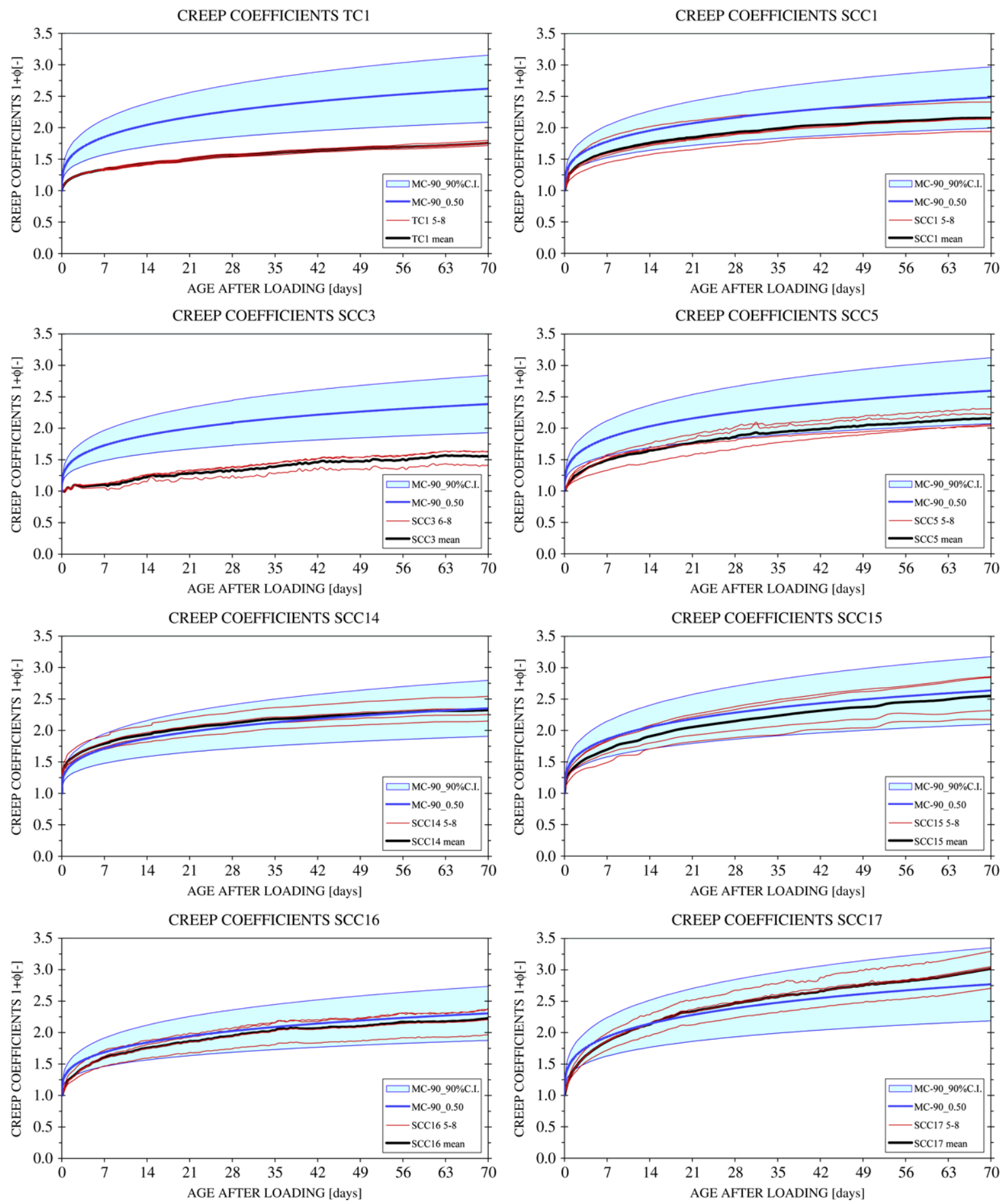

Fig. 8. Creep coefficient measurements for each mixture, including MC-90 model $90 \%$ confidence interval.

long-term deformation predictions for limestone powder type SCC. It should also be stated that the prediction models are based on empirical relations, calibrated by means of laboratory tests (creep in compression) on structural concretes, which were all traditionally vibrated. ${ }^{2}$

Besides the mean time-dependent deformation predictions, the corresponding $90 \%$ confidence intervals are also taken into account

\footnotetext{
2 MC-90 was already published in 1993, while SCC was only introduced for the first time in Europe in the mid 1990's with the European Brite EuRam Project BRPRCT96-0366, "Rational production and improved working environment through using self-compactingconcrete".
}

here (assuming a normal distribution of the deformations concerned), due to possible prediction errors caused by (a) an inherent scatter of the shrinkage and creep deformation measurements, (b) model errors and (c) general uncertainties caused by e.g. randomness of material properties and environmental conditions. The upper and lower bound values of the total shrinkage strain and creep coefficient predictions are calculated according to Eqs. (4) and (5), respectively:

$$
\begin{array}{lc}
\varepsilon_{c s}(t)=(1 \pm 0.576) \cdot \varepsilon_{c s, 0.50}(t) & (C V=35 \%) \\
\phi\left(t, t^{\prime}\right)=(1 \pm 0.329) \cdot \phi_{0.50}\left(t, t^{\prime}\right) & (C V=20 \%)
\end{array}
$$




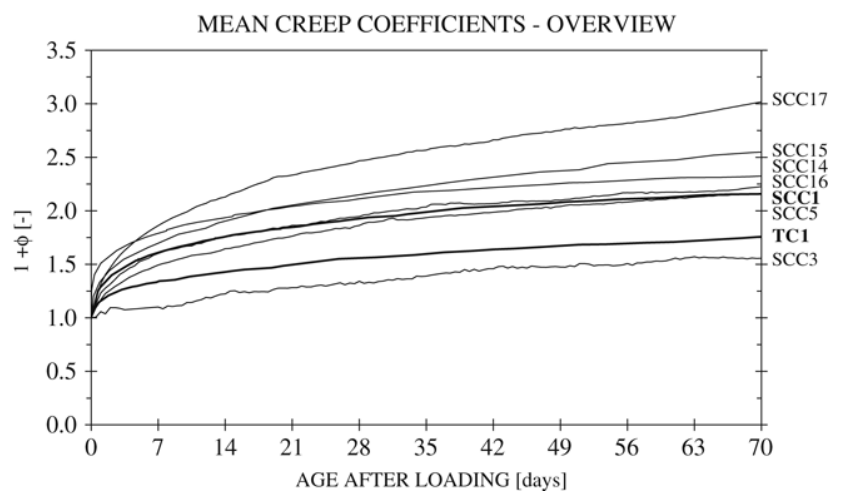

Fig. 9. Creep coefficient measurements, overview of mean creep coefficients.

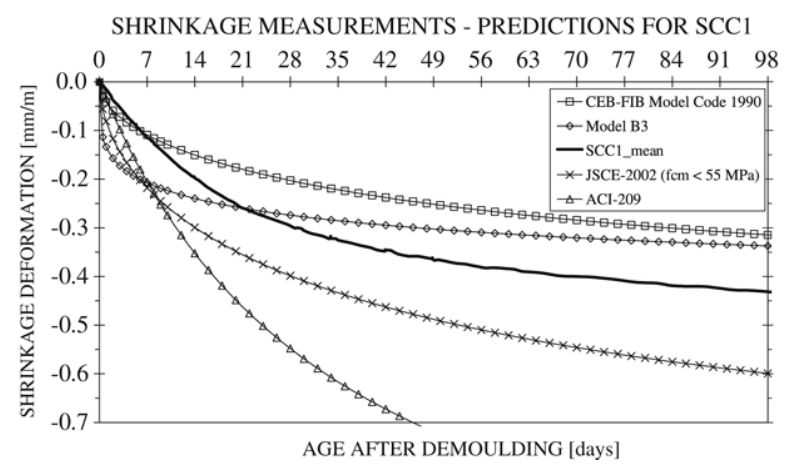

Fig. 10. Prediction of mean shrinkage deformations for SCC1, according to different models.

with $\varepsilon_{c s, 0.50}(t)$ the mean total shrinkage strain prediction $[\mathrm{mm} / \mathrm{m}]$ and $\phi_{0.50}\left(t, t^{\prime}\right)$ the mean creep coefficient prediction [-]. CV is the coefficient of variation [\%] (values according to MC-90).

The results of the mean total shrinkage strain prediction and the corresponding $90 \%$ confidence interval for the different mixtures under consideration are shown in Fig. 5. In general, the experimental mean total shrinkage deformation of the traditionally vibrated concrete mixture TC1 is very well predicted by the mean total shrinkage strain prediction $\varepsilon_{c s, 0.50}(t)$, while the experimental mean total shrinkage behaviour of the limestone powder type SCC mixtures is underestimated by $\varepsilon_{c s, 0.50}(t)$, particularly for young concrete aged up to $14 \mathrm{~d}$. This observation is also found in the $28 \mathrm{~d}$ before the creep specimens were loaded (and thus only subjected to shrinkage deformations). The underestimated mean shrinkage deformations of the (limestone) powder type SCC mixtures can be explained by the fact that the MC-90 model does not take into account any "mix composition" parameter (e.g. the use of mineral additions or chemical admixtures, water or cement content, $\mathrm{W} / \mathrm{C}$-ratio, amount of fine aggregates, ...). However, predicting shrinkage (and creep) properties of concrete from the concrete mix composition is an extremely difficult problem for which no good theory has yet been developed. [38] The shrinkage tests revealed that the experimental mean total shrinkage behaviour of the limestone powder type SCC mixtures is better estimated by the $95 \%$ upper bound total shrinkage strain prediction $\varepsilon_{c s, 0.95}(t)=$ $1.576 \cdot \varepsilon_{c s, 0.50}(t)$.

The results of the mean total strain prediction and the corresponding 90\% confidence interval are shown in Fig. 7 . It was found that the overall deformations of all SCC mixtures are rather well estimated by the mean total strain prediction (except for SCC17, where the total deformations were underestimated, due to its high water/cement ratio: $\mathrm{W} / \mathrm{C}=0.60$ ). For TC1, the overall deformations are overestimated by the mean total strain prediction.
The results of the mean creep coefficient prediction and the corresponding 90\% confidence interval are shown in Fig. 8. It was found that the creep coefficients of the SCC mixtures are, in general, rather well estimated by the mean creep coefficient prediction, while the creep coefficient of TC1 is overestimated by its prediction.

It should be noted that similar remarks in terms of shrinkage and creep were made in the European guidelines for SCC [39]: "Tests performed on creep and shrinkage of different types of SCC and a reference concrete show that: the deformation caused by shrinkage may be higher; the deformation caused by creep may be lower and the value for the sum of the deformations due to shrinkage and creep are almost similar". Besides, it is stated in [39] that (in terms of the time-dependent behaviour prediction of SCC) "the values and formulae given in the Eurocode 2 for normal concrete are still valid in the case of SCC". However, as it will be shown in the next paragraph, it is the authors' conviction that in cases of concrete structures sensitive to shrinkage, the shrinkage model given in MC-90 (and thus in Eurocode 2 ) should be adapted in order to properly consider the statistical analyses with estimation of the 95\% upper bound values.

\subsection{Modification of the model code 1990 time-dependent deforma- tion models for (limestone) powder type SCC}

According to [38], the following approximate classification of sensitivity levels in terms of shrinkage and creep can be made:

- Level 1 (low sensitive). Reinforced concrete beams, frames and slabs with spans under $20 \mathrm{~m}$ and heights up to $30 \mathrm{~m}$, plain concrete footings, retaining walls.

- Level 2. Prestressed beams or slabs of spans up $20 \mathrm{~m}$, high-rise building frames up to $100 \mathrm{~m}$ high.

- Level 3. Medium-span box girder, cable-stayed or arch bridges with spans up to $80 \mathrm{~m}$, ordinary tanks, silos, pavements.

- Level 4. Long-span prestressed box girder, cable-stayed or arch bridges; large bridges built sequentially in stages by joining parts; large gravity, arch or buttress dams; cooling towers; large roof shells; very tall buildings.

- Level 5 (highly sensitive). Record span bridges, nuclear containments and vessels, large off-shore structures, large cooling towers, record-span thin roof sheels, record-span slender arch bridges.

Besides, it is mentioned that statistical analyses with estimation of the $95 \%$ upper bound values are mandatory for level 5, highly recommended for level 4 , and desirable but not necessary for levels 1 to 3.

For that reason, the following modification of the MC-90 timedependent deformation models is advised by the authors to be used when limestone powder type self-compacting concrete is applied, since it was found above that the experimental mean total shrinkage behaviour of the limestone powder type SCC mixtures is better estimated by the $95 \%$ upper bound total shrinkage strain prediction $\varepsilon_{c s, 0.95}(t)=1.576 \cdot \varepsilon_{c s, 0.50}(t)$ :

$$
\begin{aligned}
& \varepsilon_{c s}^{*}(t)=(1 \pm 0.329) \cdot 1.576 \cdot \varepsilon_{c s, 0.50}(t) \quad(C V=20 \%) \\
& \phi^{*}\left(t, t^{\prime}\right) \equiv \phi\left(t, t^{\prime}\right)=(1 \pm 0.329) \cdot \phi_{0.50}\left(t, t^{\prime}\right) \quad(C V=20 \%)
\end{aligned}
$$

with $\varepsilon_{c s}^{*}(t)$ the total shrinkage strain prediction for limestone powder type SCC, $\phi^{*}\left(t, t^{\prime}\right)$ the creep coefficient prediction for limestone powder type SCC (same as MC-90), $\varepsilon_{c s, 0.50}(t)$ the mean total shrinkage strain prediction according to MC-90 $[\mathrm{mm} / \mathrm{m}]$ and $\phi_{0.50}\left(t, t^{\prime}\right)$ the mean creep coefficient prediction according to MC-90 [-].

Based on the experimental SCC shrinkage data, it was found that the coefficient of variation could be reduced from 35\% to $20 \%$ in case of the total shrinkage strain prediction. An explanation 
Modified MC-90 model for limestone powder type SCC:

$\varepsilon_{c s}^{*}(t)=(1 \pm 0.329) \cdot 1.576 \cdot \varepsilon_{c s, 0.50}(t)$

Eq. (6)

$\varepsilon_{c s, 0.50}(t)=$ mean total shrinkage strain prediction.

SHRINKAGE DEFORMATIONS SCC1

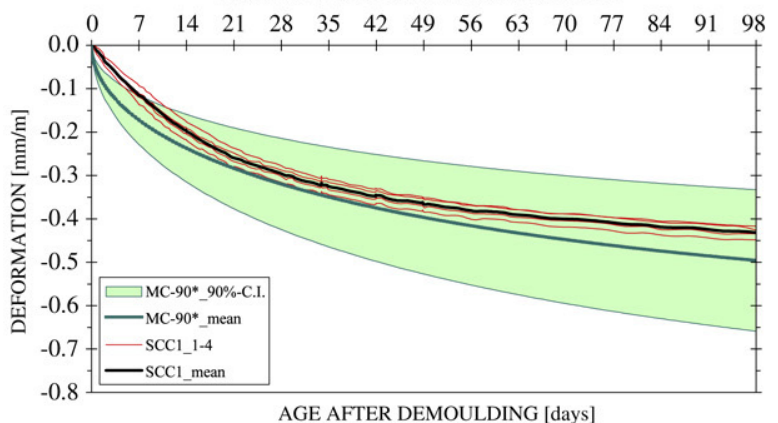

SHRINKAGE DEFORMATIONS SCC 3

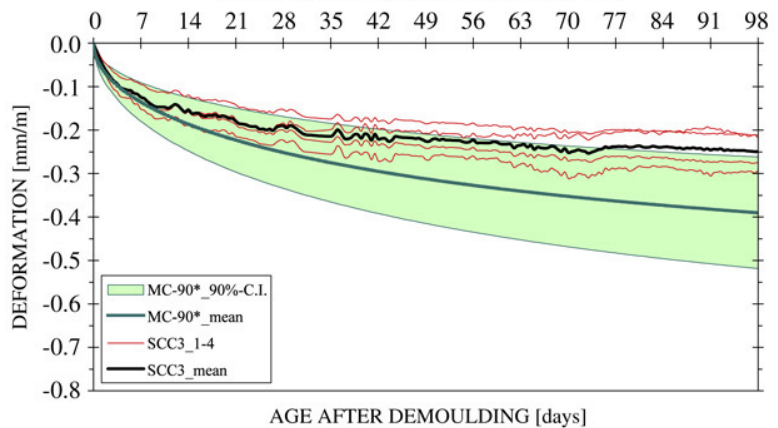

SHRINKAGE DEFORMATIONS SCC14

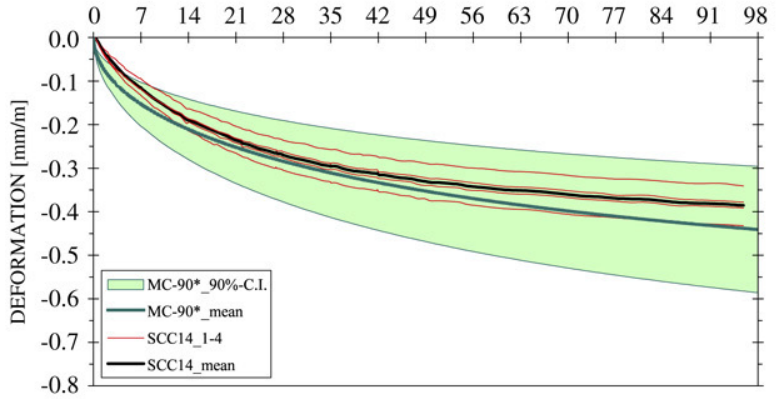

AGE AFTER DEMOULDING [days]

SHRINKAGE DEFORMATIONS SCC16
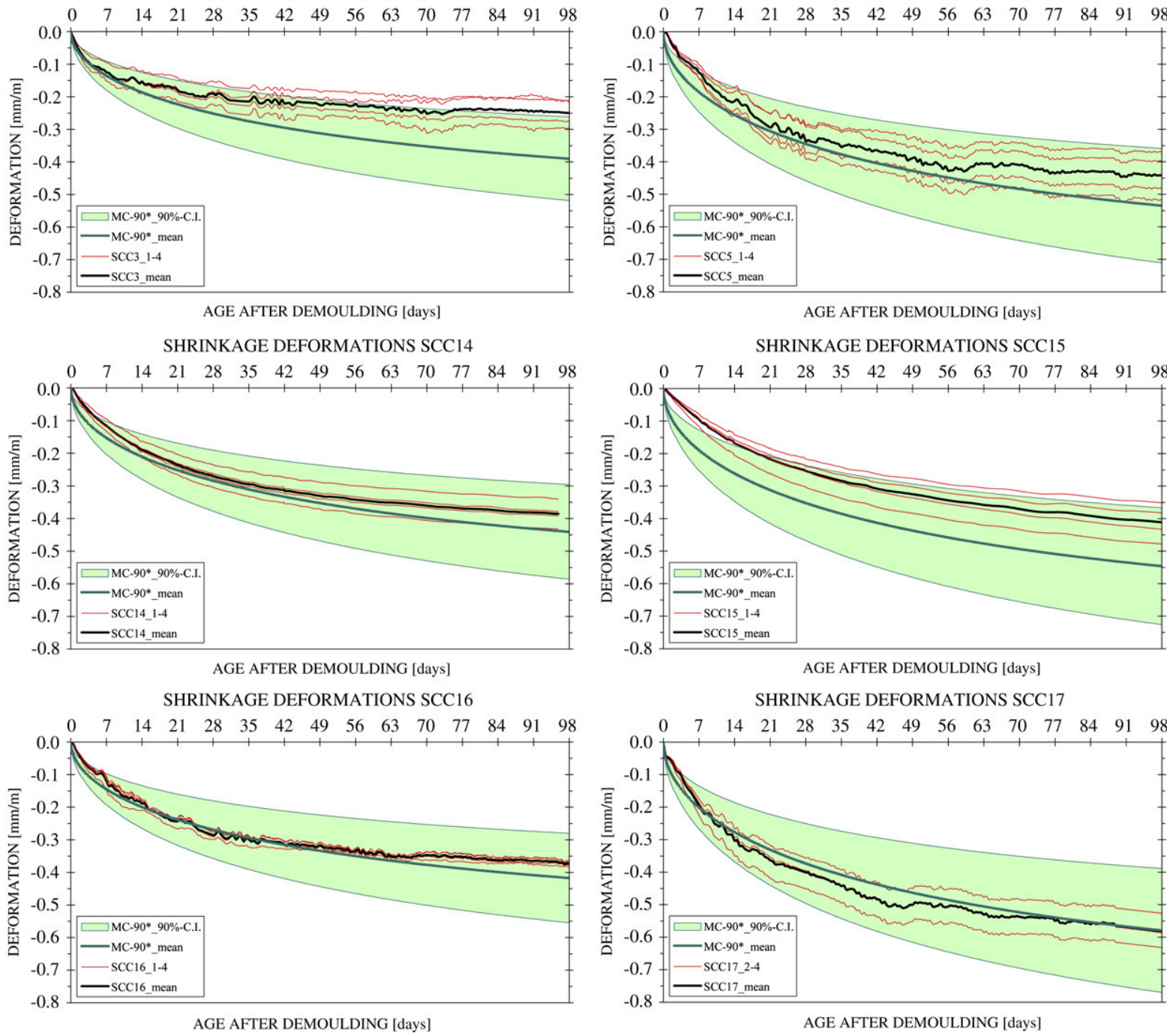

AGE AFTER DEMOULDING [days]

SHRINKAGE DEFORMATIONS SCC15

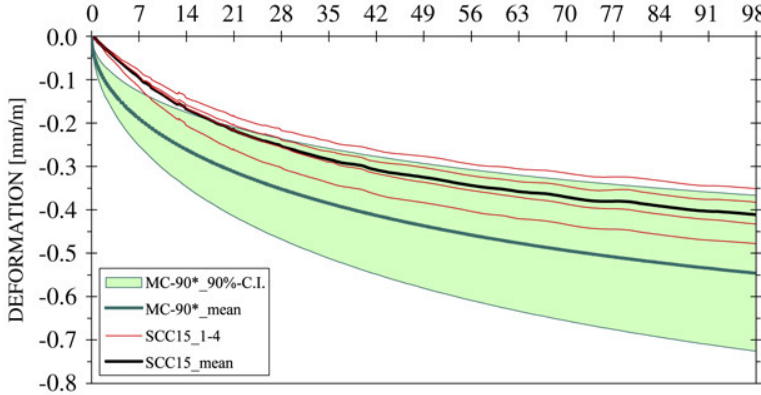

AGE AFTER DEMOULDING [days]

SHRINKAGE DEFORMATIONS SCC17

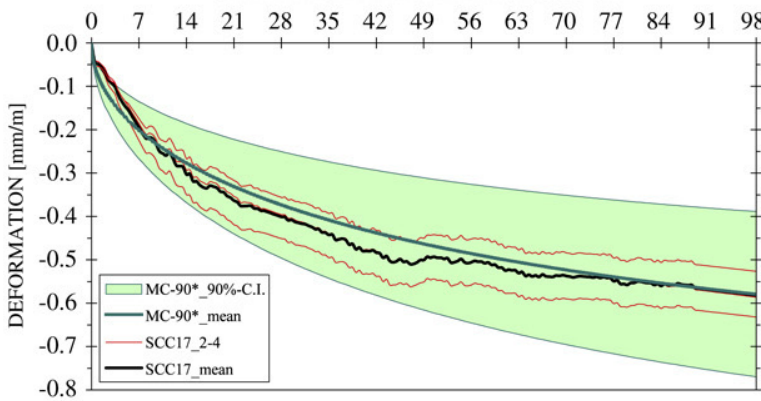

AGE AFTER DEMOULDING [days]

Fig. 11. Shrinkage measurements for each mixture, including the modified MC-90 model (MC- $\left.90^{*}\right) 90 \%$ confidence interval.

for the reduction possibility is given by the higher degree of homogeneity for the SCC mixtures, due to the elimination of vibrations, resulting in smaller uncertainties caused by material properties randomness. Based on the experimental SCC creep data, it was found that the coefficient of variation could not be reduced. Here, extra possible prediction errors caused by the inherent scatter of the creep loading seemed to overshadow the positive effect of the SCC mix homogeneity.

For the limestone powder type SCC mixtures, the results of the mean total shrinkage strain prediction and the mean total strain prediction, including the corresponding 90\% confidence interval, according to the modified model (MC-90*) are shown in Figs. 11 and 12 respectively (together with the corresponding experimental data).

Two remarks should be made in terms of the proposed model modification:

- The model modification is based on preliminary results from an ongoing work and thus may be not the final one, since only 7 different limestone powder type SCC mixtures were tested. For that reason, additional powder type SCC mixtures are tested in a sequel Belgian research project concerning the "influence of mineral additions and chemical admixtures in SCC on microcracking and durability" [40]. In this project, started 
Modified MC-90 model for limestone powder type SCC:

$\varepsilon_{c s}^{*}(t)=(1 \pm 0.329) \cdot 1.576 \cdot \varepsilon_{c s, 0.50}(t)$

$\phi^{*}\left(t, t^{\prime}\right) \equiv \phi\left(t, t^{\prime}\right)=(1 \pm 0.329) \cdot \phi_{0.50}\left(t, t^{\prime}\right) \quad E q .(7)$

$\varepsilon_{c s, 0.50}(t)=$ mean total shrinkage strain prediction and $\phi_{0.50}\left(t, t^{\prime}\right)=$ mean creep coefficient prediction, both according to MC-90.

TOTAL DEFORMATIONS SCC3

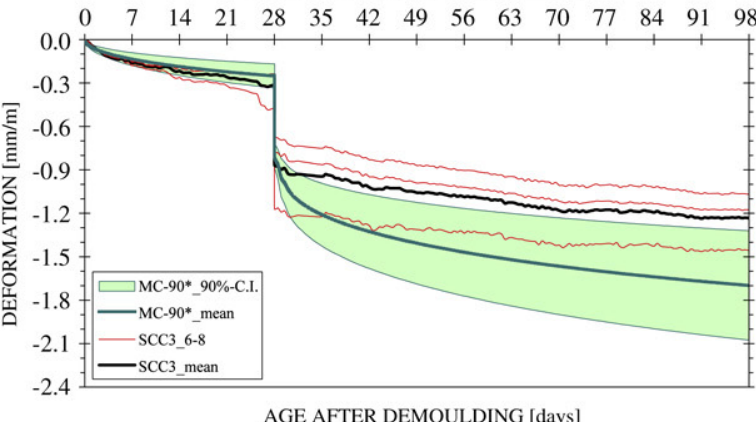

TOTAL DEFORMATIONS SCC14
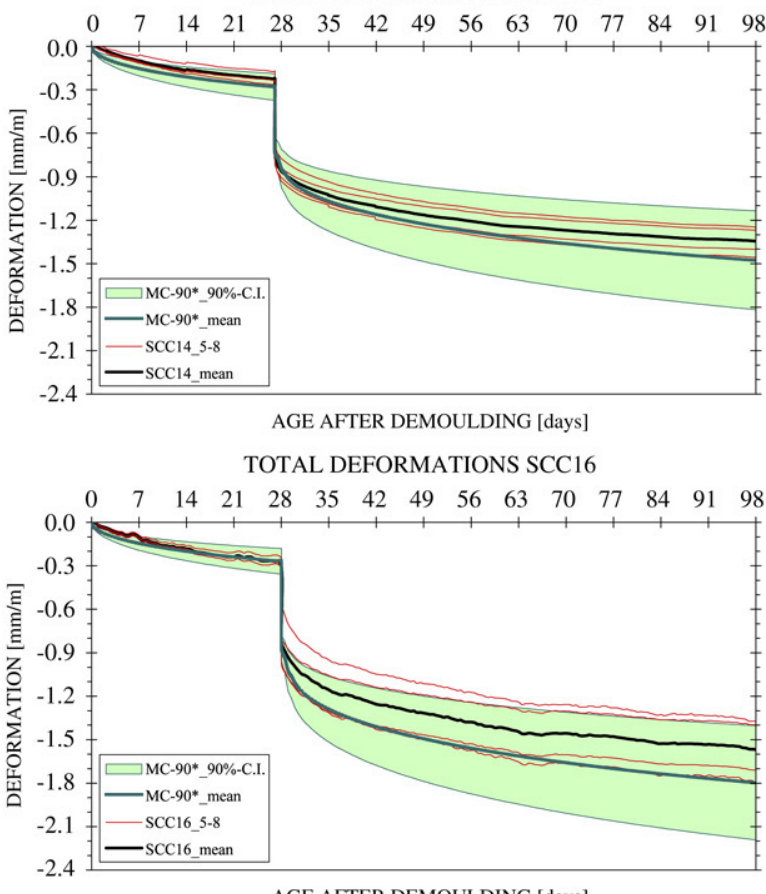

AGE AFTER DEMOULDING [days]
TOTAL DEFORMATIONS SCC1

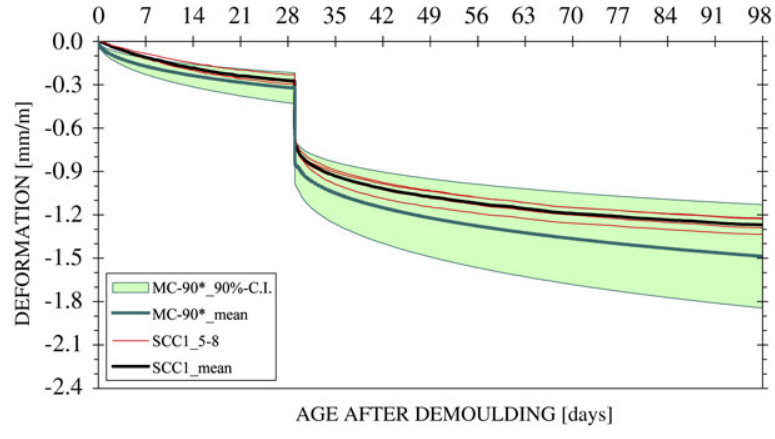

TOTAL DEFORMATIONS SCC5

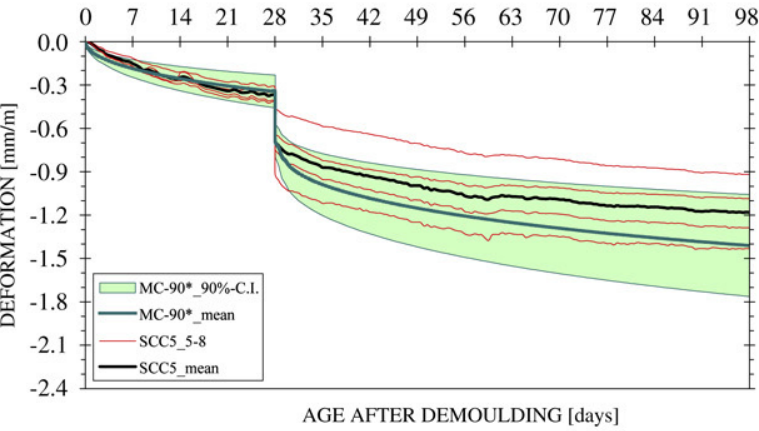

TOTAL DEFORMATIONS SCC15

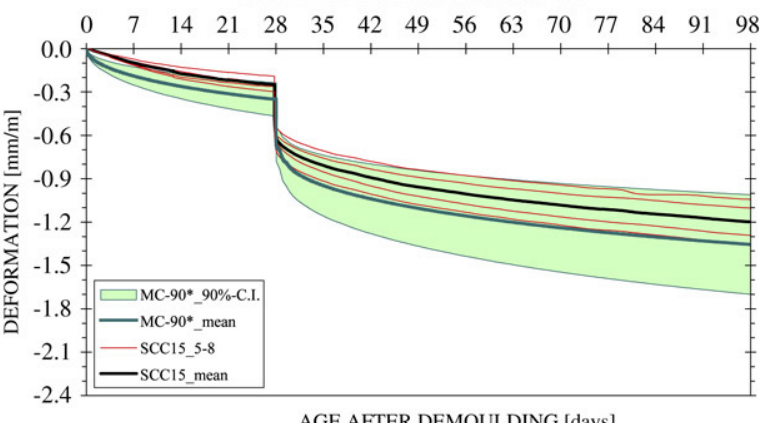

TOTAL DEFORMATIONS SCC17

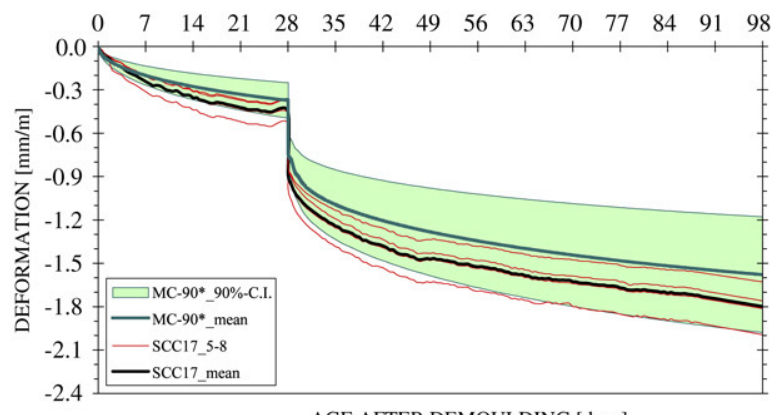

AGE AFTER DEMOULDING [days]

Fig. 12. Total deformation measurements for each mixture, including the modified MC-90 model (MC- $\left.90^{*}\right) 90 \%$ confidence interval.

January 2006, the influence of other mineral additions like quartzite filler and fly ash on the time-dependent deformation behaviour will also be investigated.

- The experimental shrinkage data revealed that a good curing practise is necessary for the limestone powder type SCC mixtures. Indeed, curing is important for the top-surface of elements made with SCC, since these can dry quickly because of an increased paste volume, a lower water/powder ratio and a lack of bleed water at the surface. Initial curing should therefore start as soon as practicable after casting and finishing in order to minimise the risk of shrinkage cracks caused by early age moisture evaporation [39]. It should be noted that during the test program, no curing of the test specimens was applied, resulting in a higher drying shrinkage component compared to well cured concrete surfaces. In the latter case, MC-90 may possibly well predict the shrinkage behaviour of limestone powder type SCC without modification (as also mentioned in [39], see above).

However, within those limitations, the great benefit of the model modification proposed here is given by the fact that only the constant product factor of the total shrinkage strain is changed in order to predict the time-dependent deformations for limestone 
powder type SCC. In this way, the above mentioned philosophy of MC-90 can be pursued for the time-dependent behaviour prediction of limestone powder type SCC.

\section{Concluding remarks}

An experimental programme has been set up in order to examine the time-dependent behaviour (shrinkage and creep) of limestone powder type self-compacting concrete, using readily available materials in Belgium. For the SCC mixtures, the total amount of powder (cement + limestone powder) was fixed at $600 \mathrm{~kg} / \mathrm{m}^{3}$ and the amount of PCE superplasticizer was determined in order to obtain a suitable flowability without segregation. Parameters like the type of cement, the cement/powder ratio, the water/cement ratio and the type of aggregate were being investigated.

Test results revealed generally higher shrinkage and creep deformations for the SCC mixtures compared with the TC1 mix. However, whereas the shrinkage deformations are underestimated by CEB-FIP Model Code 1990 (MC-90), the creep and overall behaviour of the limestone powder type SCC mixtures are rather well predicted by the same model. In order to properly predict the time-dependent behaviour of limestone powder type SCC in cases of concrete structures (highly) sensitive to shrinkage and creep, a modification of the MC-90 in terms of the total shrinkage strain prediction is proposed by the authors. For creep, test results revealed that the MC-90 creep coefficient prediction could remain unmodified for limestone powder type SCC application.

\section{Acknowledgment}

The financial support of the Research Programme of the Research Foundation - Flanders (FWO) is greatly acknowledged.

\section{References}

[1] Okamura H, Ouchi M. In: Skarendahl Å, Petersson Ö, editors. Proc. 1st int. RILEM symp. on SCC. Bagneux: RILEM Publications SARL; 1999. p. 3-14.

[2] Ye G, Liu X, De Schutter G, Poppe AM, Taerwe L. Influence of limestone powder used as filler in SCC on hydration and microstructure of cement pastes. Cem Con Comp 2007;29(2):94-102.

[3] CEB, editor. Revisions of the design aids of the CEB Design Manual 'Structural effects of time-dependent behaviour of concrete' in accordance with the CEBFIP Model Code 1990. Lausanne: CEB; 1993.

[4] Kim JK, Han SH. In: Malhotra VM, editor. Proc. of the 3rd CANMET/ACI int. conf. on high-performance concrete: Design, materials and recent advances in concrete technology. Malaysia: ACI; 1997. p. 637-52.

[5] Hu C, Barcelo L. M. Ouchi (Ed.) ISC-Workshop, Proc. of the int. workshop on SCC. 1998. p. 228-42. CD-ROM.

[6] Rols S, Ambroise J, Péra J. Effects of different viscosity agents on the properties of self-levelling concrete. Cem Con Res 1999;29(2):261-6.

[7] Bissonnette B, Pierre P, Pigeon M. Influence of key parameters on drying shrinkage of cementitious materials. Cem Con Res 1999;29(10):1655-62.

[8] Gram H, Piiparinen P. In: Skarendahl Å, Petersson Ö, editors. Proc. 1st int. RILEM symp. on SCC. Bagneux: RILEM Publications SARL; 1999. p. 211-25.

[9] Bui V, Montgomery D. In: Skarendahl Å, Petersson Ö, editors. Proc. 1st int. RILEM symp. on SCC. Bagneux: RILEM Publications SARL; 1999. p. 227-38.

[10] Persson B. In: Skarendahl Å, Petersson Ö, editors. Proc. 1st int. RILEM symp. on SCC. Bagneux: RILEM Publications SARL; 1999. p. 239-50.

[11] Persson B. A comparison between mechanical properties of self-compacting concrete and the corresponding properties of normal concrete. Cem Con Res 2001;31(2):193-8.

[12] Ludwig H, Hemrich W, Weise F, Ehrlich N. The new concrete: self compacting concrete - principles and practice (2). BFT 2001;67(6):58-67.

[13] Johansen K, Hammer T. Drying shrinkage of 'Norwegian' self-compacting. Nordic Concrete Research 2002;27:35-41.
[14] Raghavan KP, Sarma B, Chattopadhyay D. In: Shah SP, Daczko JA, Lingscheit J, editors. Proc. of the 1st North American conf. on the design and use of selfconsolidating concrete. Chicago: Hanley Wood; 2003. p. 307-11.

[15] Attigbe E, See HT, Daczko JA. In: Shah SP, Daczko JA, Lingscheit J, editors. Proc. of the 1st North American conf. on the design and use of self-consolidating concrete. Chicago: Hanley Wood; 2003. p. 331-6.

[16] Ma J, Dietz J, Dehn F. In: Wallevik Ó, Nielsson I, editors. Proc. 3rd int. RILEM symp. on SCC. Bagneux: RILEM Publications SARL; 2003. p. 136-42.

[17] Pons G, Proust E, Assié S. In: Wallevik Ó, Nielsson I, editors. Proc. 3rd int. RILEM symp. on SCC. Bagneux: RILEM Publications SARL; 2003. p. 645-54.

[18] Poppe AM. Influence of Mineral Additions on Hydration and Properties of Self-Compacting Concrete. (PhD dissertation), Ghent University; 2004. Only available in Dutch.

[19] Poppe AM, De Schutter G. In: Yu Z, Shi C, Khayat KH, Xie Y, editors. 1st int. symp. on design, performance and use of SCC. Bagneux: RILEM Publications SARL; 2005. p. 329-36.

[20] Collepardi M, Borsoi A, Collepardi S, Troli R. In: Shah SP, editor. Proc. of the combined 2nd North Am. conf. on the design and use of SCC and the 4th int RILEM symp. on SCC. Chicago: Hanley Wood; 2005. p. 911-20.

[21] Seng V, Shima H. In: Shah SP, editor. Proc. of the combined 2nd North Am. conf. on the design and use of SCC and the 4th int. RILEM symp. on SCC. Chicago: Hanley Wood; 2005. p. 981-6.

[22] Skarendahl Å, Petersson Ö. Self-compacting concrete, state-of-the-art report of RILEM technical committee 174-SCC. Bagneux: RILEM Publications SARL; 2000.

[23] CEB-FIP, editor. Model code 1990 - design code. London: Thomas Telford; 1993.

[24] Bažant ZP. Creep and shrinkage prediction model for analysis and design of concrete structures - model B3. Mater Struct 1995;28(180):357-65.

[25] ACI Committee 209, editor. Prediction of creep, shrinkage and temperature effects in concrete structures (209R-92). Farmington Hills: American Concrete Institute; 1990.

[26] JSCE, editor. Standard specification for concrete structures - 2002 materials and construction. Tokyo: Japan Society of Civil Engineers; 2005.

[27] Boel V, Audenaert K, De Schutter G, Heirman G, Vandewalle L, Desmet B, Vantomme J. Transport properties of potentially aggressive media in selfcompacting concrete and relation with durability - Final report of Belgian research project G.0018.02, sponsored by the Research Programme of the Research Foundation - Flanders (FWO); 2005.

[28] Vandewalle L, Mortelmans F. The concrete way to development. In: FIP, editor Proc. of the FIP symp. Johannesburg: FIP; 1997. p. 491-501.

[29] Vandewalle L. Concrete creep and shrinkage at cyclic ambient conditions. Cem Con Comp 2000;22(3):201-8.

[30] Bonen B, Shah SP. Fresh and hardened properties of self-consolidating concrete. Prog Struct Engng Mater 2005;7(1):14-26.

[31] Bonen B, Shah SP. In: Kovler K, Marchand J, Mindess S, Weiss J, editors. Proc. of the int. RILEM symp. on concrete science and engineering: A tribute to Arnon Bentur. Bagneux: RILEM Publications SARL; 2004. p. 43-56.

[32] Holschemacher K, Klug Y. A database for the evaluation of hardened properties of SCC. LACER 2002;7:123-34

[33] Boel V. Microstructure of self-compacting concrete in relation with gaspermeability and durability aspects. Ph.D. dissertation. Ghent University; 2006. Only available in Dutch.

[34] Heirman G, Vandewalle L, Boel V, Audenaert K, De Schutter G, Desmet B, d'Hemricourt J, Vantomme J. In: Kovler K, editor. Proc. of the int. RILEMJCI seminar on concrete durability and service life planning: Curing, crack control, performance in harsh environments. ConcreteLife'06, Bagneux: RILEM Publications SARL; 2006. p. 13-23.

[35] Acker P, Ulm FJ. Creep and shrinkage of concrete: physical origins and practical measurements. Nucl Eng Des 2001;203(2-3):143-58.

[36] Bažant ZP, Wittmann FH. Creep and shrinkage of concrete structures. New York: Wiley; 1982.

[37] Chern JC, Chan YW. Deformations of concretes made with blast furnace slag cement and ordinary Portland cement. ACI Mat J 1989;86(4):372-82.

[38] Bažant ZP, Baweja S. Creep and shrinkage prediction model for analysis and design of concrete structures. In: Al-Manaseer A, editor. The Adam Neville symposium: Creep and shrinkage - structural design effects. ACI SP-194, Farmington Hills: American Concrete Institute; 2000. p. 1-83.

[39] BIBM, CEMBUREAU, EFCA, EFNARC and ERMCO. The European guidelines for self-compacting concrete: Specification, production and use, May 2005, pp. 63

[40] Heirman G, Vandewalle L, Van Gemert D, Elsen J, Boel V, Audenaert K, De Schutter G, Desmet B, Vantomme J. In: De Schutter G, Boel V, editors. Proc. of the 5th int. RILEM symp. on SCC. Bagneux: RILEM Publications SARL; 2007. p. 773-8. 